\title{
A Tribute to Jim Gray
}

\section{ERIC ALLMAN}

Computer science attracts many very smart people, but a few stand out above the others, somehow blessed with a kind of creativity that most of us are denied. Names such as Alan Turing, Edsger Dijkstra, and John Backus come to mind. Jim Gray is another.

Jim was a giant in computer science, and yet curiously unassuming in person. He would sit quietly at our ACM Queue editorial board meetings, feeling no need to dominate the conversation. When he did speak up, however, everyone in the room would shut up and listen (a difficult feat with that group!), because we all knew that anything Jim had to say would be relevant and interesting. He was also one of the most active board members between meetings, despite being one of those with the most demands on his time. He bore those demands well and with grace. When you talked with Jim on the phone, you could tell that he wasn't reading his e-mail or cleaning up his desk-he was entirely with you-and he never seemed to be in a rush.

I first met Jim when I was an undergraduate at U.C. Berkeley working on the thennew field of relational database management systems. Jim (who received the first Ph.D. in computer science ever granted at Berkeley) was working at IBM Research on a competing project, yet he quickly became one of my first mentors. He seemed particularly to enjoy working with bright young people, including, of course, many students. Passing on information was his great passion.

One of Jim's last projects was the Sloane Digital Sky Survey (http://sdss.org). Bill Gates was said to have asked Jim why he wanted to work on a project that had no possible profit motive, to which Jim responded, "Precisely, that's the point." He wanted to do the best work he could and share it with as many people as possible, and he knew that once money got involved, everything would change. To him, the draw of the sky survey was that it gave him a chance to work with the largest database available that consisted entirely of public data, and he could share everything he created. And besides, it was cool.

Perhaps what I found most impressive about Jim was his ability to say things with a profound clarity. He had a knack for studying contentious issues and then publishing the definitive paper that made the solution clear to everyone. His analyses were so simple, so succinct, and so obviously correct that the debate was over, allowing the field to move on to the next big challenge, which Jim would, of course, be watching carefully. 
Despite all of his significant accomplishments, my memories are of Jim the manwho liked to laugh and had a fondness for Ridge Zinfandels, who was devoted to his family, loved being outdoors, and was deeply spontaneous. One day in October a few years ago, during a visit my partner and I made to see Jim and his wife, Donna, in San Francisco, we were walking around North Beach and came across a vendor selling pumpkins. Jim immediately bought several of them and we went back to his place to carve them. The rest of us came up with jack-o-lanterns that were about what you would expect from nerds: all straight lines and triangles. But Jim's was a work of art, composed mostly of curves, with prominent eyebrows and full lips that were laughing.

On January 28, 2007, Jim took out his sailboat, Tenacious, destined for the Farallon Islands. It was a beautiful day, sunny, with minimal wind and perfect visibility, and Jim had plenty of safety gear. He was never seen again. No wreckage was found, despite a massive search by both the U.S. Coast Guard and many of the top people in the computer industry. A huge amount of data was collected, including everything from satellite data to underwater sonar imagery, inspiring development of new imageprocessing algorithms. I think Jim would have liked that the search for him spawned new research.

Over the next several months, Queue Magazine will be running a series of some of Jim's best works as a tribute to his massive contributions, both to this magazine and the entire field. This month we're leading off with "Distributed Computing Economics" from 2003. Jim does some back-of-the-envelope calculations to compare the costs of networking, computation, database access, and database storage and produces some results that are in some cases inconsistent with common thought. As a comparison, we've put a similar paper from 1987 on the Web (http://acmqueue.org/special/Gray_5Minute Rule.pdf) called "The 5 Minute Rule for Trading Memory for Disc Accesses and the 10 Byte Rule for Trading Memory for CPU Time." Although the economics are out of date ( $\$ 5,000$ per megabyte for main memory?), the methodology remains interesting, and Jim specifically talks about how technology changes will alter these trade-offs.

Also in this issue we are publishing "Ode to a Sailor" by Donna Carnes, Jim's wife, written as the introduction to the proceedings of a public tribute to Jim (http://www. eecs.berkeley.edu/IPRO/JimGrayTribute/), held at U.C Berkeley May 31. Donna has kindly permitted us to reprint it. Although it references papers not included in this issue of Queue, it gives a personal, even intimate, picture of Jim, which we feel is appropriate. Q

ERIC ALLMAN is chief science officer of Sendmail. Along with Jim Gray and others, he is a founding member of Queue's editorial advisory board. 